Part of Journal of Research of the National Bureau of Standards, Volume 27, December 1941

\title{
FLUIDITY OF TRITON F AND XANTHATE SOLUTIONS AS A MEASURE OF CELLULOSE DEGRADATION
}

\author{
By Ralph T. Mease and Leland F. Gleysteen ${ }^{1}$
}

\section{ABSTRACT}

Dimethyldibenzylammonium hydroxide (Triton F) and sodium hydroxide solutions containing carbon disulfide were compared with cuprammonium solution with regard to their suitability as solvents for cellulose for fluidity measurements. Cuprammonium solution dissolves low-fluidity celluloses more readily than does either Triton $\mathrm{F}$ or the xanthating mixture. Although any of the solutions could be used for evaluating cellulose, the latter have no advantage over cuprammonium as a standard solvent.

\section{CONTENTS}

Page

I. Introduction

II. Preparation of celluloses of different degrees of degradation $\ldots \ldots \ldots \ldots 44$

III. Fluidity measurements.

IV. Results and discussion

V. Summary

VI. References

\section{INTRODUCTION}

The fluidity of a solution of a cellulosic textile in some suitable solvent is a sensitive measure of the extent to which the cellulose has been degraded, for example, by bleaching agents, acids, alkalies, light, or mildew. Cuprammonium has been used extensively [1] ${ }^{2}$ as the solvent, but considerable care and special equipment are required for its preparation, storage, and use [2]. Accordingly, the possibility of using other solvents was investigated.

Certain quaternary ammonium bases swell cellulose and in some instances dissolve it. Dimethyldibenzylammonium hydroxide, hereafter called Triton $\mathrm{F}$, the name used by the manufacturer, ${ }^{3}$ is a good solvent for cellulose $[3,4,5]$. Sodium hydroxide-carbon disulfide mixtures convert cellulose to cellulose xanthate, and the fluidities of the xanthate solutions are related [6] to the quality of the cellulose.

The xanthate mixture has been used in some commercial laboratories for evaluating celluloses of special kinds, such as wood pulps. The present study is concerned with conditions under which celluloses of widely different degrees of degradation can be evaluated with the

\footnotetext{
1 Research Associate at the National Bureau of Standards, representing the Textile Foundation.

2 Figures in brackets indicate the literature references at the end of this paper.

3 The Triton $\mathrm{F}$ used in the experiments was obtained through the courtesy of Röhm \& Haas Co., 222 West Washington Square, Philadelphia, Pa.
} 
aid of the three solvents. The advantages and disadvantages of each solvent are discussed.

\section{PREPARATION OF CELLULOSES OF DIFFERENT DEGREES OF DEGRADATION}

Cotton cellulose in the form of unbleached muslin cloth was used for this work. The muslin was first desized by steeping it overnight in a solution of a starch- and protein-solubilizing enzyme. It was then agitated for 2 hours in a boiling 1-percent solution of sodium hydroxide, rinsed with distilled water, then with 1-percent acetic acid, and again with water. The muslin was then dried and lightly pressed with a warm iron and cut from selvage to selvage into strips 7 inches wide.

Specimens were degraded to various extents by steeping them in hydrochloric acid and by overbleaching with calcium hypochlorite, and the effect of these treatments upon the breaking strength of the cloth was determined. The results of the fluidity tests can thus be related to data having direct practical value.

To prepare celluloses modified by acid, strips of the desized, alkaliboiled muslin were kept for 24 hours at $21^{\circ} \mathrm{C}$ in 1.01, 1.95, 2.92, 3.94, 4.90 , and $5.98 N$ hydrochloric acid. The samples were removed, rinsed with distilled water, then with 0.5-percent ammonium hydroxide solution, extracted for about 16 hours with distilled water, and dried.

The chlorine solution for bleaching was prepared by making a paste with calcium hypochlorite and water. It was clarified by settling, and the supernatant liquid was drawn off and adjusted to contain approximately 1 percent of available chlorine. Strips of the desized muslin were steeped in the solution for $1 / 2,1,4,9,16$, and 30 hours at $21^{\circ} \mathrm{C}$. After the steeping, the muslin was rinsed with a 1-percent solution of sodium dithionite $\left(\mathrm{Na}_{2} \mathrm{~S}_{2} \mathrm{O}_{4}\right),{ }^{4}$ rinsed with distilled water, and dried.

Specimens for the measurements of breaking strength were prepared by cutting the 7-inch strip of muslin into strips 6 inches long and $1 \frac{1}{4}$ inches wide, with the warp yarns running lengthwise. Warp yarns were raveled from the edges until the strips were about 1 inch in width, each having 51 warp yarns. The strips were conditioned at 65-percent relative humidity at $70^{\circ} \mathrm{F}$, and tests of breaking strength were made by the raveled-strip method [8] on a pendulumtype testing machine. The results are given in figures 1 and 2 .

\section{FLUIDITY MEASUREMENTS}

The broken strips of muslin were used for the fluidity measurements. They were chopped in a laboratory Wiley mill to prepare well-mixed samples. This also facilitated attack by the solvents, although it did not degrade the cellulose.

All the solutions were prepared to contain $0.5 \mathrm{~g}$ of dry cellulose in $100 \mathrm{ml}$ of solution.

The methods used for the preparation of cuprammonium solutions of cellulose and the measurement of their fluidities were the same as those previously described [2].

- Nomenclature recommended by the Committee of the International Union of Chemistry for the Reform IInorganic Chemical Nomenclature, 1940 [7]. 
To dissolve cellulose in Triton $\mathrm{F}$ and in sodium hydroxide solutions containing carbon disulfide, the cellulose and reagents were placed in a mixing vial with glass plunger, described elsewhere [9], and rotated for 16 to 18 hours at $45^{\circ}$ to $50^{\circ} \mathrm{C}$.

In preparing viscose solutions for fluidity measurements, the required amount of cellulose was placed in the mixing vial and the air

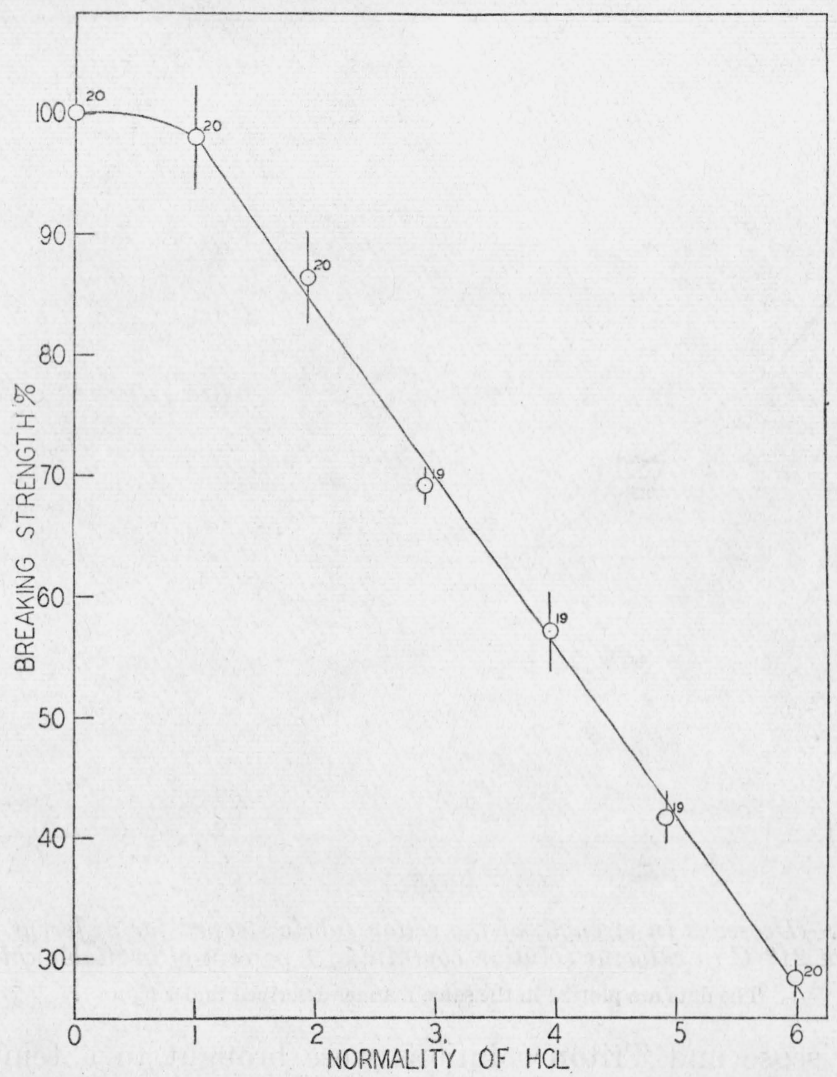

Figure 1.-Changes in strength of the cotton fabric on treatment at $21^{\circ} \mathrm{C}$ for 24 hours with hydrochloric acid of different concentrations.

The marked portiuns on the ordinates passing through the points represent the standard deviations for the respective values. The adjacent numerals are the number of observations, whose means are the points plotted.

in the vial swept out with a gentle stream of nitrogen. An amount. of 16-percent sodium hydroxide solution, equal to $1 / 4$ of the volume (exclusive of plunger) of the vial, was added. The cellulose was permitted to soak for one quarter to one half hour, and afterwards an amount of carbon disulfide equal to five times the weight of the cellulose was added. The vial was then filled with a 7-percent solution of sodium hydroxide and rotated for 45 to 50 hours at a temperature of 15 to $18^{\circ} \mathrm{C}$.

Pipette viscometers commonly used for measuring the fluidity of cuprammonium solutions of cellulose [2] were used, without modification, for measuring the fluidity of the viscose solutions. For the 
Triton $\mathrm{F}$ solutions, which were more viscous, the same type of viscometer was used, except that the capillary discharge tube was larger, about $1.56 \mathrm{~mm}$ in diameter. All the viscometers were calibrated by the graphical method of Higgins $[10,11]$. Those for the Triton $\mathbf{F}$ solution were calibrated with three oils of fluidities of approximately $0.52,3.1$, and 5.8 rhes.

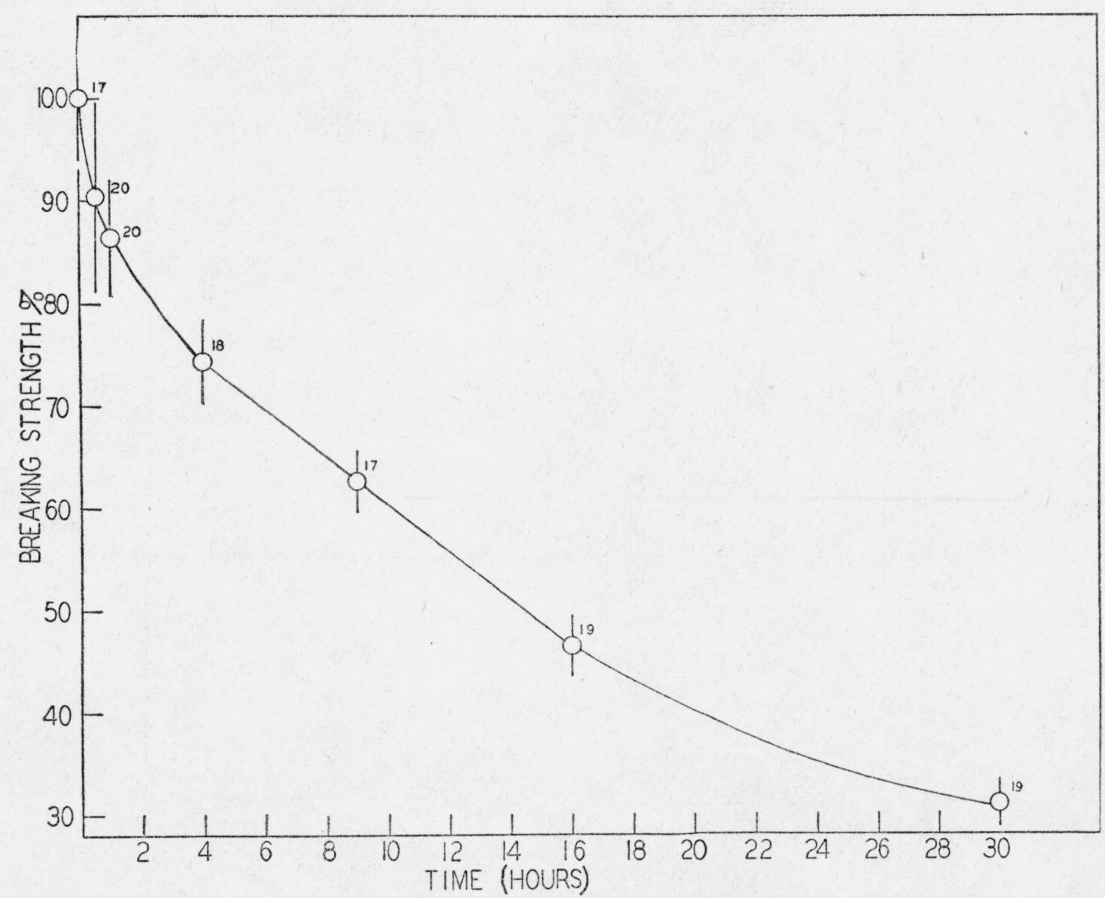

FigURE 2.-Decrease in strength of the cotton fabric steeped for different periods of time at $21^{\circ} \mathrm{C}$ in chlorine solution containing 1 percent of available chlorine.

The data are plotted in the same manner described under figure 1.

The viscose and Triton solutions were brought to a temperature of $21^{\circ} \mathrm{C}$ and poured into the viscometer also at $21^{\circ}$. The flow measurements were made in the usual manner.

\section{RESULTS AND DISCUSSION}

The results of the fluidity measurements are given in figure 3 . For comparison, the Triton fluidity values were multiplied by 10 to make them nearly equal to the cuprammonium fluidities. This is the ratio found by other investigators [3]. It is apparent that any of the three solvents can be used.

The reproducibility of the results obtained was approximately equal for the three solutions in evaluating cellulose treated with hydrochloric acid. Therefore, the slopes of the curves in figure 3 may be taken as a measure of the relative sensitivity of the test. With the bleached muslin, however, the uncertainty of the measurements with the Triton F solution was about four times as great as that with the cuprammonium. 
Although it may be concluded that the results obtained with either Triton F or mixtures of carbon disulfide and sodium hydroxide could be used instead of those obtained with cuprammonium solution for evaluating cellulose for some purposes, a comparison of the techniques required by each is desirable.

A concentration of Triton $\mathrm{F}$ of $1.96 \mathrm{~N}$ has been shown to be the best for dissolving cellulose $[3,4]$ and was used in these experiments. Although the Triton $\mathrm{F}$ rapidly swells cellulose, celluloses having a fluidity of 5 rhes or less in a 0.5 -percent solution in cuprammonium

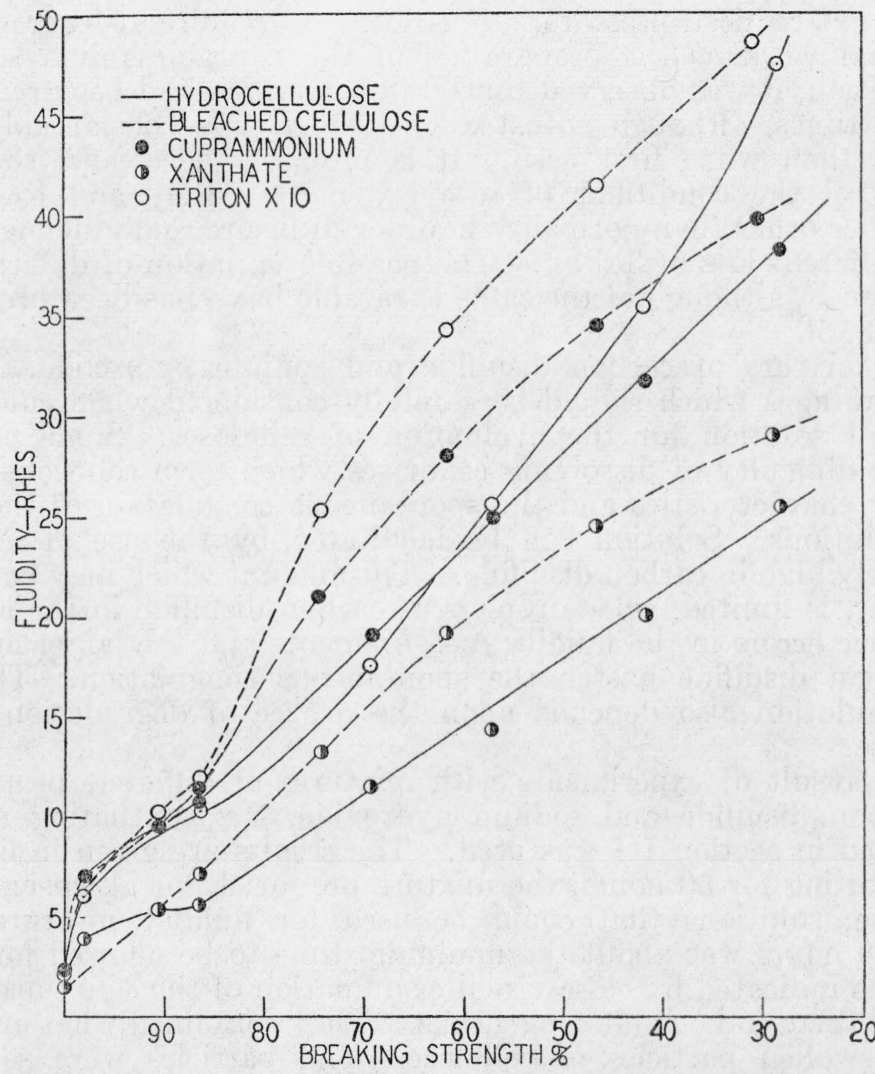

FIGURE 3.-Breaking strengths and fluidities of acid-treated muslin (hydrocellulose) and of chlorine-treated muslin.

require at least several hours to become homogeneously dispersed in Triton $\mathrm{F}$ at room temperatures. This was found to be true whether the mechanical agitation was applied by stirring, by shaking, or by a plunger in a closed container in the manner ordinarily used for dissolving cellulose in cuprammonium. Solutions of high-grade celluloses in the Triton are often clear in appearance but show swollen masses when the mixture is poured slowly from one vessel into another. The use of a water bath at 45 to $50^{\circ} \mathrm{C}$ while dissolving the cellulose increases the effectiveness of the agitation and facilitates dispersion. When agitated for 15 to 20 hours at this temperature, all the celluloses usually formed solutions suitable for measurements of fluidity. 
Less time is required for preparing solutions of cellulose in cuprammonium. It is usually convenient, however, to permit the agitation to proceed overnight. Thus the time to be allotted for dissolving cellulose in either Triton or cuprammonium solution may be considered the same.

When this work was undertaken, Triton $\mathrm{F}$ was not readily available. Accordingly, it was recovered by the method described by Russell and Woodberry [3] and was used repeatedly. The recovery requires the addition of a considerable volume of reagents, and the concentration of the diluted Tri on by the removal of water by distillation at reduced pressure. $\mathrm{T}$ is seems to require at least as much time and work as the prepara ion of the cuprammonium solution. In addition, it was observed that Triton $\mathrm{F}$ which had been recovered several times, although adjusted to $1.96 \mathrm{~N}$, was considerably more viscous than when first used. It is probably necessary, therefore, to control the conditions of recovery more closely and to specify properties other than normality in order to insure reproducible results with different lots of Triton. The possible variation of different lots of Triton F, although of the same titratable base, has been previously noted $[3,5]$.

The mixture of carbon disulfide and sodium hydroxide also has disadvantages which should be carefully considered when choosing a standard solution for the evaluation of celluloses. Some of these are the difficulty of dissolving celluloses which form solutions of low fluidity characteristics and the spontaneous coagulation of the cellulose solutions. Solution can be facilitated by the use of mixtures relatively high in carbon disulfide. The amount which may be added, however, is limited, since droplets of carbon disulfide in the solution introduce errors in the fluidity measurements and the larger amounts of carbon disulfide hasten the spontaneous coagulation. The rate of coagulation also depends upon the degree of degradation of the cellulose.

As a result of experiments with mixtures of different proportions of carbon disulfide and sodium hydroxide, the xanthating mixture described in section III was used. The results are given in figure 3. By agitating for 50 hours, the mixture produced, for all specimens of cellulose, solutions that could be used for fluidity measurements. That 50 hours was about the minimum time to be allowed for agitation was indicated by close visual examination of the solutions, which showed them to be nonhomogeneous. They contained what appeared to be swollen particles of cellulose. The particles were so small, however, that they did not interrupt the flow through the capillary of the viscometer. Although coagulation of the cellulose from these solutions took place after considerable time, changes in the solutions occurred very slowly. Fluidity measurements of fair reproducibility could be made within a few hours after agitation for 50 to 75 hours.

\section{SUMMARY}

Chemical degradation in cotton fabrics, exhibited by changes in breaking strength, can also be evaluated by fluidity measurements on solutions of the cotton in Triton F, sodium hydroxide-carbon disulfide mixture, or cuprammonium solution.

The sensitivity of the measurements in detecting changes in cellulose was found to be approximately the same for the three solutions 
when evaluating cellulose degraded by acid. The sensitivity was least for the Triton when used on chlorine-bleached cotton.

Both Triton F and sodium hydroxide-carbon disulfide mixtures were found to require longer times to disperse unmodified cotton cellulose in a state satisfactory for fluidity measurements than is required by cuprammonium solution.

A comparison of the technique, time required, precision and sensitivity of the results obtained showed no advantage in substituting either Triton F or sodium hydroxide-carbon disulfide mixture as standard solvents in place of cuprammonium for evaluating celluloses of widely different states of degradation.

\section{REFERENCES}

[1] Charles Dorée, Methods of Cellulose Chemistry (Chapman \& Hall, Ltd., London, 1933).

[2] J. Research NBS 22, 271-284 (1939) RP1179.

[3] Ind. Eng. Chem., Anal. Ed. 12, 151 (1940).

[4] J. Textile Inst. 32, T32-T44 (1941).

[5] J. Textile Inst. 32, T57-T79 (1941).

[6] Kolloid-Z. 88, 215-223 (1939).

[7] J. Am. Chem. Soc. 63, 889 (1941).

[8] Textikes; General Specifications, Test Methods, Federal Specification CCCT-191a, April 23, 1937. Government Printing Office, Washington, D. C. Price $5 \dot{\phi}$.

[9] J. Research NBS 27, 551 (1941) RP1442.

[10] Nat. Phys. Lab. Collected Researches 11, pt. 2, Viscometry 3 (1914).

[11] Am. Soc. Testing Materials. Symposium on Consistency, New York, N. Y., June 29, 1937.

WASHington, September 12, 1941. 